of everything written on this subject. A small membership fee will be charged to persons who would like to assist in the development of this work, for which they will receive abstracts or data of what has been written and copies of any future publications. To others, not members, a research fee will be charged for abstracts and copies of papers. The income from this source and from endowments will eventually build up a very rich library and bureau of literature of immense value for the future. Every one interested in helping on this movement should address the secretary, Miss C. F. Stoddard, 23 Trull Street, Boston. Every author of books or papers that bear on the subject of alcohol or narcotics, either direetly cir indirectly, should send copies to the above address. These papers will be filed, catalogued and put away where they can be used on any future occasion. A large number of distinguished men have become members and the organization is non-partisan in the broadest sense of the word.

T. D. Crothers, M.D.

\section{Quinin-and-Urea Hydrochlorid in Malaria.}

Piriladelphia, June 28, 1907.

To the Editor:-In the demonstrations which, following the recent meeting of the American Medical Association, I gave to visiting members, in the medical ward at Jefferson Hospital, I had the opportunity to illustrate the treatment of malarial fever by hypodermic injections of quinin-and-urea hydrochlorid. The patient was a young man with double tertian infection. The injection was made shortly after a paroxysm. According to prediction a paroxysm appeared on the succeeding day, but there were no further paroxysms for six and three-fourths and thirteen and one-half days respectively, although organisms were found in the peripheral blood (also according to prediction) on the fifth and twelfth days respectively, having been absent in the meanwhile. I have made this demonstration repeatedy in my public clinics at the Philadelphia Hospital, and published it oceasionally, during the last fifteen or sixteen years. My object in now publishing it again is to ask observers who have skill and opportunity to test, by blood taken from the spleen or other deep source, whether, during the resting period of something less than fourteen days, conjugation of microgametes and macrogametes takes place in the human (avian or animal) body. A single injection of 0.7 to $1 \mathrm{gm}$. ( 10 to $15 \mathrm{gr}$ ) in a syringeful- 1.5 to 2 c.c. $(20$ to $30 \mathrm{~m}$.) $\longrightarrow$ of sterilized distilled water, thrown deeply under the skin, and preferably about two hours before an anticipated paroxysm, will secure this non-paroxysmal period of between thirteen and fourteen days in single tertian and between six and seven days in double tertian infection, in almost every case. I have tested it 100 times. According to the time (in relation to the paroxysm) at which the injection is given, and also according to other factors as yet undetermined, the period at which organisms can again be discovered peripherally, varies somewhat, as does likewise the form in which the paroxysm recurs. Sometimes there is full chill, fever and sweat; sometimes only rise of temperature without other disturbance; and between these extremes many varieties. of course, the injection must be made carefully and aseptically. But if this be done and the point of puncture painted with tincture of iodin, or sealed with iodoform-collodion or sterile collodionized cotton, there will be no local injury.

The coincidence between the 6 to 7 days and 12 to 14 days' periods of freedom respectively following the injection of this most powerful of the quinin salts with the periods of the pre-cystic and post-cystic stages and entire sporogonic (mosquito) cycle of the malarial organism-especially when we recall the old clinical observations of recurrent paroxysms on the seventh and fourteenth days - is suggestive of some fundamental relation between the various phenomena. Just what it is remains to be proved, but it must be connected in some way with a cycle of development different from the ordinary schizogony, that occurs somewhere in the body of the infected person. The "quantitative" explanation does not seem to be

1. The Polyclinle, Philadelphia, March, 1893, p. 66 .

2. Sometimes it has seemed that they could be found more readils at night, but the elements of the problem are not sufficiently clear to warrant an unqualified statement. sufficient. It would also be of interest to observe the effect, if any, of a very weak solution of the drug on the development of the organism in the mosquito. Solomon Solis-(OHEN.

\section{Beware of an Alleged Repair Man.}

Scraxton, Pa., July 1, 1907.

To the Editor:-Physicians using electric appliances should beware of a man giving his name as "Dr." C. P. Hoffman, claiming connection with Van Houten \& Ten Broeck of New York, and proposing to repair appliances. He contracted to clean and rebuild my static machine (June 15, 1907), and to take two days (himself and assistant). They worked spasmodically three hours and packed their tools (while I was absent about 15 minutes) and skipped, leaving my machine one-third torn down and useless, having broken several plates and caused me an unlimited amount of trouble. He is a fram , certainly no mechanic, and I take this oceasion to warn the profession against being swindled. Noreover, I would be pleased to hear of any one he has treated similarly to myself.

\section{). IV. Euxs, M.D.}

\section{The Alexander Cancer "Cure."}

PiIlladelpiria, July 8, 1907.

T'o the Lditor:-Referring to the editorial in Tile JounNaL, July 6,1907 , on the publication in Leslie's Weelily of the report of an alleged clinic asserted to demonstrate the usefulness of Alexander's so-called cancer "cure," I would call your attention to a reprint of the article, issued as an advertising circular, so soon after the publication you have criticised as to leave little rom to doubt the commercial origin and connection of both.

The old code of ethics of the American Medical Association well said, concerning nostrums, that their proprietors must con. fess either to gross inhumanity or to fraudulent avarice. Surely this applies in a peculiar degree to alleged cures for cancer. If a real discovery has been made in the treatment of this sad affection, it should be published to the world, as Beard has published his experience with trypsin and amylopsin, as Jacobi has published his use of methylene blue, and as all other physicians worthy of the name, publish their discoveries, their experience and their suggestions. Concealment could only be for the sake of gain, and to characterize it as inhuman avarice would be mild. But when such concealment exists there is no reason to believe that a genuine discovery has been made; rather is it to be concluded that to inhuman avarice fraud, equally inhuman, has been added. Leslie's Weckly; therefore, even if deceived, has lent itself to inhuman avarice; and if not deceived, it has lent itself to inhuman avarice and fraud.

Solomon Solis-Cohen.

\section{Queries and Minor Notes}

Axongmols Communications will not be noticed. Quelies for this column must be accompanied by the writer's name and address, but the request of the writer not to publish name or address will be faithfully observed.

\section{GRAMS AND MILLIGRAMS.}

Chicago, June 28, 1907.

To the Editor:-In the "Laboratory Manual" by Dr. B. Fantus, p. 21, I find this clear and cogent rule: "In reading quantities including several denominations, only one unit is used, thus $0.065 \mathrm{gm}$. is read 65 milligram ( $65 \mathrm{mg}$.) not $6 \frac{1}{2}$ centiglam, nor 65 thousandth of a gram." Now, applying the above rule or any other rational rule, how would you read w. A. Jolley's table 2 on p. 1718, rule, how would you read W. A. Jolley's table 2 on p. 1718,
vol. xlviii, er this: "Dose of atropin is $0.0004 \mathrm{gm}$. or $0.4 \mathrm{mg}$." ? Now what I can not understand is what are the exact words, that is, written, read, or spoken words, to express entirely the "unit" 0.0004 $\mathrm{gm}$ ? If I may not say what I am cautioned not to say in Fantus rule, then I' am completely "stuck." We easily. say or read 1.0 c.c., or 15.0 c.c., but what is correct reading for 0.3 c.c., is it 3 tenths of a c.c.?
A. H. DE NExDozA, M.D.

Axswer-Among chemists, who use these terms more than any one else, it is customary to use as denominations of weight the gram and milligram, omitting the intermediate terms and occasionally using the term kilogram. Following this custom quantities smaller than a milligram would be spoken of as decimal fractions of a milliglam, but would be written as fractions of a gram. A similar 